\title{
Infrared \& Microprobe Studies of intrusions \& micro-inclusions in diamond
}

\author{
Beard, A.D. and Milledge, H.J.
}

Research School of Geological \& Geophysical Sciences, Birkbeck \& University College London, Gower St., London WC1E 6BT, United Kingdom.

Information on the genesis and subsequent history of diamonds in the Mantle has generally been sought by studying the composition of mineral inclusions well protected by the host diamond, so that no interaction with external material can have occurred since they were enclosed. However, many diamonds exhibit fractures which contain inclusions which must either have penetrated existing cracks from outside the specimen or escaped via these cracks, whether or not they were actually responsible for their formation. Other diamonds when recovered contain minerals exposed in holes, though these are generally removed during the recovery process except for exploration samples or small stones which sometimes escape the cleaning process.

Examples of such material which have received considerable attention are the phosphate inclusions in carbonado, which appear to be secondary occupants of pores and cracks. If carbonado is a mantlederived form of diamond, as seems increasingly likely, then one might expect other other imperfect diamonds from the same area to contain similar intrusions, and if they do not do so, this reinforces the case for some unique origin for carbonado.

An example of diamonds with material frequently attached to their surfaces are the specimens from New South Wales, many of which have holes and cracks which frequently contain specific minerals, and are the subject of a separate study. In this poster we discuss three types of material:

1) A large, approximately cubic, diamond which has small clear octahedral sectors, but in which the dominant cubic sectors have extensive cracks many of which reach the exterior of the stone. The cracks broaden into substantial holes in some cases, and the inclusions in these holes contain a number of distinct minerals of variable composition (Fig.1), and an interesting feature of these holes and cracks is that they are edged with a thin layer of diamond which, when seen in cathodoluminescence, appears to be distinct from the main stone, suggesting that it was a later addition after the crack had formed.

2) Plates from coated stones, which contain micro inclusions (Navon et. al, 1988) for which the composition appears to change from one zone to the next. Previous measurements made on microinclusions just below the surface of the polished coat on another plate had suggested that this might be the case, and micro-inclusions measured along a traverse (Fig 2.) for a plate in which substantial numbers of such inclusions could be seen in the back-scattered image gave the normalised elemental percentage values shown in Fig 3. The x-rays from subsurface inclusions will be attenuated by the few microns of diamond through they must escape, the lightest elements being most attenuated, and true inclusion compositions would need to be corrected for this effect, but ratios for elements with similar X-ray energies will be comparable.

3) Ten small Jagersfontein diamonds, on which a pair of windows had been polished for infrared spectroscopy because they contain very large and poorly defined inclusions surrounded by clear white diamond of approximately octahedral habit, had in seven cases exposed the central inclusions. In all cases the clear region showed a small amount of fully aggregated IaB nitrogen with no platelet peak, while the 
central area showed the presence of $\mathrm{CO}_{2}$, as in many George Creek diamonds (Schrauder and Navon (1993), Chinn et al, (1995)). Microprobe analyses showed the dominant inclusion as native iron distributed in the diamond matrix with some silicon, orthopyroxne, and phlogopite. $\mathrm{SiO}_{2}$ was also found in cracks, but not yet identified as quartz or coesite. Table 1 contains selected microprobe analysis of phases in the central inclusions in four of the diamonds.

\begin{tabular}{|c|c|c|c|c|c|c|c|}
\hline Table 1. & $\begin{array}{c}\text { Jag 2 } \\
\text { opx }\end{array}$ & $\begin{array}{c}\text { Jag 5 } \\
\text { opx }\end{array}$ & $\begin{array}{c}\text { Jag 10 } \\
\text { opx }\end{array}$ & $\begin{array}{c}\text { Jag 2 } \\
\text { phl }\end{array}$ & $\begin{array}{c}\text { Jag 9 } \\
\text { phl }\end{array}$ & $\begin{array}{c}\text { Jag 9 } \\
\text { phl }\end{array}$ & $\begin{array}{c}\text { Jag 9 } \\
\text { Fe-Si }\end{array}$ \\
\hline $\mathrm{SiO} 2$ & 45.29 & 39.3 & 45.17 & 36.24 & 38.92 & 37.57 & 14.71 \\
$\mathrm{TiO} 2$ & 0.1 & 0 & 0.32 & 1.17 & 2.02 & 1.23 & 0 \\
$\mathrm{Al2O} 3$ & 1.06 & 4.15 & 0.87 & 7.15 & 9.59 & 7.47 & 1.9 \\
$\mathrm{FeO}$ & 3.56 & 16.45 & 8.38 & 6.62 & 10.63 & 9.8 & 63.07 \\
$\mathrm{MnO}$ & 0 & 0 & 0 & 0.1 & 0 & 0 & 0 \\
$\mathrm{Cr} 2 \mathrm{O} 3$ & 0 & 0.11 & 0.1 & 0 & 0.42 & 0.13 & 0.22 \\
$\mathrm{MgO}$ & 40.51 & 33.56 & 41.21 & 20.26 & 20.43 & 20.81 & 6.39 \\
$\mathrm{CaO}$ & 0.36 & 0 & 0.15 & 0.81 & 0.25 & 0.53 & 0 \\
$\mathrm{Na} 2 \mathrm{O}$ & 0.58 & 1.21 & 0.78 & 0.85 & 0.83 & 0.84 & 0 \\
$\mathrm{~K} 2 \mathrm{O}$ & 0 & 0.25 & 0 & 7.26 & 8.73 & 7.19 & 0 \\
& & & & & & & \\
$\mathrm{Total}$ & 91.46 & 95.03 & 96.98 & 80.46 & 91.82 & 85.57 & 86.29 \\
\hline
\end{tabular}

\section{References}

Chinn I.L, Gurney, J.J, Milledge, H.J., Taylor, W.R. and Woods, P.A. (1995) Internat. Geol. Rev. 37, 254-8. "Cathodoluminescence Properties of $\mathrm{CO}_{2}$-Bearing and $\mathrm{CO}_{2}$-Free Diamonds from th George Creek K1 Kimberlite Dike."

Navon, O., Hutcheon, I.D., Rossman, G.R. and Wasserburg, G.J. (1988). Nature, 335, 784 - 789. "Mantle-derived fluids in diamond micro-inclusions".

Schrauder, M, and Navon, O. (1993) Nature, 365, 42 - 44. "Solid carbon dioxide in a natural diamond". 


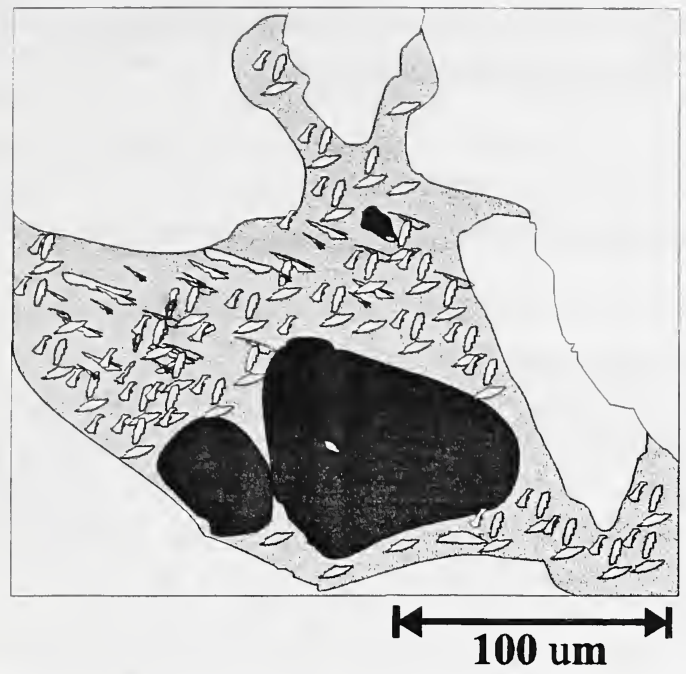

Serpentine (after olivine) with rare $\mathrm{Cr}$-spinel inclusions.

\section{Barite}

Groundmass consisting of cpx laths (light grey) in fine-grained serpentine

Diamond host

Figure 1. Typical multimineralic phase inclusion in enlarged crack in cube sectors of a large diamond plate.

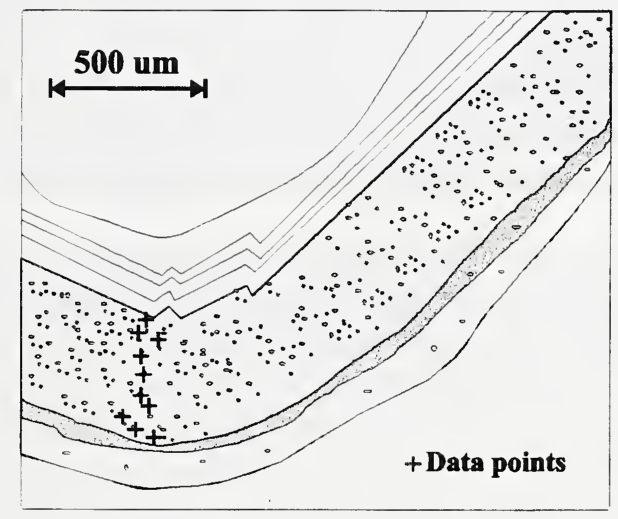

Figure 2. Schematic representation of the $\mathrm{C} / \mathrm{L}$ image of one corner of a coated stone plate showing data points where microprobe analysis of subsurface micro-inclusions $(1-2 \mu \mathrm{m})$ were taken. These gave normalised elemental analysis showing considerable compositional variation across successive growth zones (see Figure. 3).

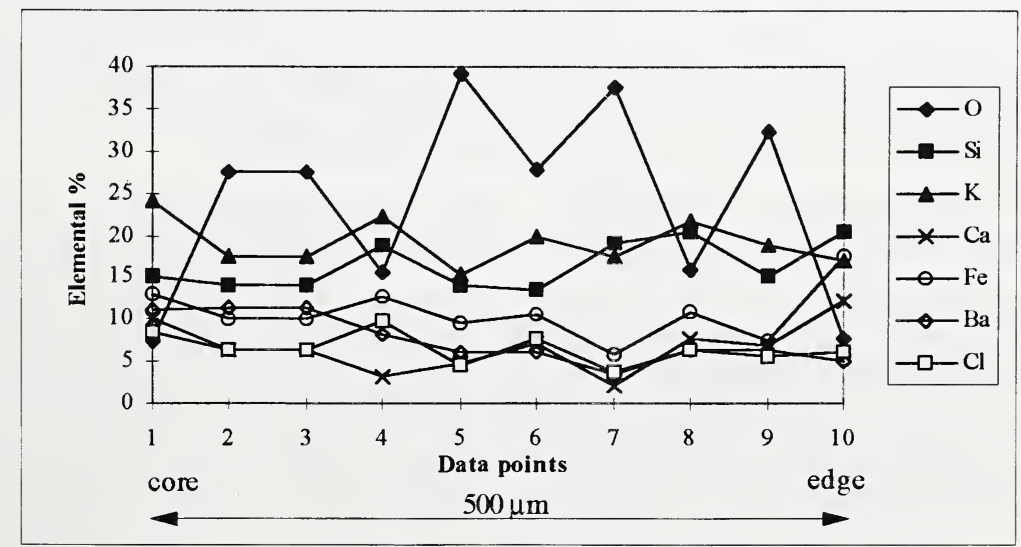

Figure 3 . 